\title{
SciDoC
}

Infer, Interpret \& Inspire Science

International Journal of Dentistry and Oral Science (IJDOS)

ISSN: $2377-8075$

\section{Proportion Of Orthodontic Patients Seeking Adult Orthodontic Treatment}

Research Article

Sandhya. $\mathrm{A}^{1}$, Harish $\mathrm{babu}^{2 *}$, Senthil Murugan $\mathrm{P}^{3}$

${ }^{1}$ Saveetha Dental College and Hospitals, Saveetha Institute of Medical and Technical Sciences (SIMATS), Saveetha University, Chennai, India. ${ }^{2}$ Senior lecturer, Department of Orthodontic dentistry, Saveetha Dental college and Hospitals, Saveetha institute of medical and technical sciences (SIMATS), Saveetha University, Chennai, India.

${ }^{3}$ Associate Professor, Department of Oral and Maxillofacial Surgery, Saveetha Dental college and Hospital , Saveetha institute of medical and technical sciences (SIMATS),Saveetha University, Chennai, India.

\section{Abstract}

The aim of the study was to assess the proportion of adults in a sample population of orthodontic patients seeking treatment. The study was conducted in a university hospital. Records of patients who underwent orthodontic treatment from June 2019 to February 2020, were examined and included in the study. A total of 41190 patient records were screened out of which 300 subjects were included in the study by simple random sampling. Patient records with chief complaints related to orthodontics only were chosen. Adults were defined as those who are aged 19 years and above. Data on age, gender, and chief orthodontic complaints were recorded. The recorded data was later methodically tabulated in a MS Excel worksheet. Tabulated data was later exported to SPSS software (SPSS version 21.0, SPSS, Chicago II, USA) for statistical analysis. The data was analysed using a chi- square test to check for association between gender and age groups. The chi square value was 0.234 and the $\mathrm{p}$ value was 0.629 ( $\mathrm{p}$ value $<0.05$ to be statistically significant). Hence there was no association between gender and adult orthodontic treatment. It was observed that $51.3 \%$ of orthodontic patients were in the age group of $19-40$ years and $43.33 \%$ were in the age group of 18 and below. It was also observed that among adults 55\% were females and $45 \%$ were males. From the results of the study it can be concluded that in a university hospital based setting, adults seeking orthodontic treatment are proportionately greater than adolescents and children and among adult patients both males and females were equally likely to seek orthodontic treatment.

Keywords: Adult Patients; Adolescents; Adult Orthodontic Treatment; Proportion.

\section{Introduction}

The aesthetic perception of one self is an important factor for adult patients seeking orthodontic treatment. These patients reported strong motivation and defined capacity in the need of treatment, as small differences in dental aesthetics can affect selfperception significantly [1] in this population group. However, there is evidence that this issue can be perceived differently by different ethnic groups [2-4]. Demographically, some social classes may perceive dental esthetics differently because of costs rather than need or demand [5]. Patients seeking orthodontic treatment are more concerned about improving their appearance and social acceptance than improving their oral health and function [6].
Adult patients were earlier daunted with the prospect of having fixed appliances to straighten teeth and correct malocclusions. However, in the past few decades, the proportion of adults seeking orthodontic treatment has been on the rise. Adults are seeking orthodontic treatment at historic levels based on their perceived aesthetic needs. [7]

Understanding the factors that determine the need for orthodontic treatment will enable better planning and also better assessment of treatment needs and patient's priorities. Gender, age, intellectual level, social class, severity of the malocclusion, dental care, and self-perception of facial esthetics are found to be associated with the desire to seek orthodontic treatment. The goals of orthodontic treatment are restoring esthetic impairments,

\footnotetext{
*Corresponding Author:

Harish babu,

Senior lecturer, Department of Orthodontic dentistry, Saveetha Dental college and Hospitals, Saveetha institute of medical and technical sciences (SIMATS), Saveetha University,

Chennai, India.

Tel :+919360575950

E-mail : harish.ortho@gmail.com

Received: May 28, 2021

Accepted: June 16, 2021

Published: July 06, 2021

Citation: Sandhya.A, Harish babu, Senthil Murugan P. Proportion Of Orthodontic Patients Seeking Adult Orthodontic Treatment . Int J Dentistry Oral Sci. $2021 ; 8(7): 3074-3078$. doi: http://dx.doi.org/10.19070/2377-8075-21000626
}

Copyright: Harish babu. ${ }^{\circ}$ 2021. This is an open-access article distributed under the terms of the Creative Commons Attribution License, which permits unrestricted use, distribu-

tion and reproduction in any medium, provided the original author and source are credited. 
improving oral health, oral function, and enhancing a patient's psychosocial well-being. Patients who seek orthodontic treatment are most likely to be concerned with the improvement of their appearance and smile as well as social acceptance in a population [8].

The rate of starting orthodontic treatment may be decided not only by the severity or prevalence of malocclusion, but also by other background factors, such as age, sex, and socioeconomic status [9-11]. It would be intriguing to analyse the influence of background factors, such as age, sex, and area of living, on the perceptions toward orthodontic treatment. Various studies have been conducted on the proportion of people undergoing orthodontic treatment such as Statistics from the United States reveal that the median percentage of adult case starts had risen from $15.4 \%$ of all cases in 1981 to $24 \%$ in 2014.Previously our team has a rich experience in working on various research projects across multiple disciplines [12-26].

Hence, the aim of this study was to determine the proportion of adult patients seeking orthodontic treatment in a university hospital.

\section{Materials And Method}

\section{Study setting and sampling}

This study is a single-center retrospective study, carried out in the Department of Orthodontics, Savettha dental college and Hospitals. The study was approved by the ethical board of Saveetha dental college- Institutional ethical committee [IEC] (SDC/ SIHEC/2020/DIASDATA/0619-0320) and was in accordance with the ethical stanzzdards that were stipulated. All available records of adult patients treated from June 2019 to February 2020, were examined and included in our data collection. Adults were defined as those who were aged 19 years and above. A total of 41190 patient records were screened out of which 300 subjects were included by simple random sampling to minimise sampling bias. Cross verification of data for error was done by presence of additional reviewers and by photograph evaluation. Two examiners were involved in the study.

\section{Data Collection/Tabulation}

Data on age, gender and chief orthodontic complaint were recorded and entered into a MS excel worksheet. The data was later exported to SPSS software (SPSS version 21.0, SPSS, Chicago II, USA) for statistical analysis.

\section{Statistical Analysis}

The statistical analysis was done using SPSS software (SPSS version 21.0, SPSS, Chicago II, USA). Descriptive statistics were used to summarise the demographic information of the patients included in this study and to analyse the frequency distribution of the data. The data was analysed using a chi- square test to check for association between gender and age groups of patients seeking orthodontic treatment.( $\mathrm{p}$ value $<0.05$ statistically significant).

\section{Results And Discussion}

The results of the study showed that among the sample population chosen, the maximum number of patients were aged 19-30 years. $51.33 \%$ of patients were in the age group of $19-30$ years and $43.33 \%$ of patients were in the age group of 18 years and below. Only $5.33 \%$ of patients were in the age group of above 30 years. Out of 300 patients, $25 \%$ were adult males, $32 \%$ were adult females. More female patients (55\%) underwent orthodontic treatment when compared to males (45\%) among the entire sample population. Chi- square test to check for association between gender and age groups showed a chi square value of 0.234 and the $p$ value was 0.629 ( $p$ value $<0.05$ to be statistically significant). The frequency curve depicts the mean age at which more number of patients underwent orthodontic treatment. It is observed that the highest frequency was observed at the mean age of 20 years. (GRAPH 4)

From this study, it is observed that only $56 \%$ of adults undergo orthodontic treatment when compared to the adolescent $(43 \%)$ [GRAPH 5]. This is similar to studies such as the study conducted by Tan $\mathrm{El}$ in which there was a significant increase in the proportion of adult orthodontic patients [7]. This study was supported with the result of study based on a questionnaire done by yoonji kim in which he stated that when compared to adults in their $20 \mathrm{~s}$ (63.2\%), those in their 40s and 50s had a lower percentage of interest in orthodontic treatment $(46.2 \%$ and $45.1 \%$, respectively; $\mathrm{p}<0.05) .[7,27]$

With the success of preventive dentistry, more patients are retaining their teeth into adulthood and more attention is being given to the orthodontic treatment needs of adults who were not given the opportunity to receive orthodontic treatment when they were younger. Some of the reasons cited for the increasing trend in adults seeking orthodontic treatment are higher aesthetic demand by adult patients, improved technology and new innovations in treatment techniques, and increased awareness and accessibility to orthodontic treatment [7].

Patients are now more conscious about their facial aesthetics, with greater emphasis on the "perfect smile."[28]. When surveyed on their motivations for pursuing orthodontic treatment, consider-

\footnotetext{
Graph 1: The bar graph showing the frequency of age wise distribution of orthodontic patients. $X$ Axis represents the age and $Y$ Axis represents the number of orthodontic patients. The highest frequency was noted at the age group 19-30 years $(51.33 \%)$ followed by the age group below 18 years $(43.33 \%)$ and above 30 years $(5.33 \%)$.
}

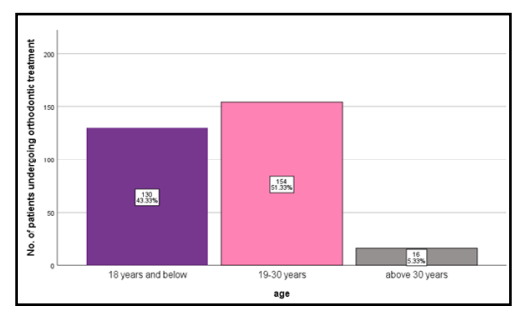


Graph 2: The bar graph showing the frequency of study population involved in the study. X Axis represents the study population and Y Axis represents the number of orthodontic patients. Out of 300 patients, $25 \%$ of them were adult males, $32 \%$ were adult females and the rest were $42 \%$.

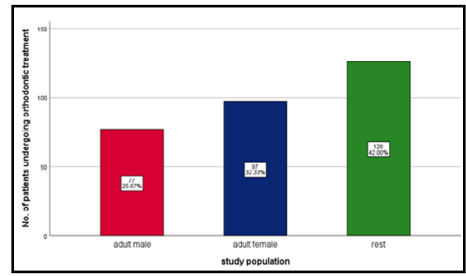

Graph 3: The bar graph represents the association between gender and the study population. The highest frequency was noted among females when compared to males. It was observed that male and female adults have undergone more orthodontic treatment when compared to the rest of the population. There was no significant difference between the gender and the study population of the orthodontic patients. ( Chi - Square, p value: $0.629(p>0.05)$ )

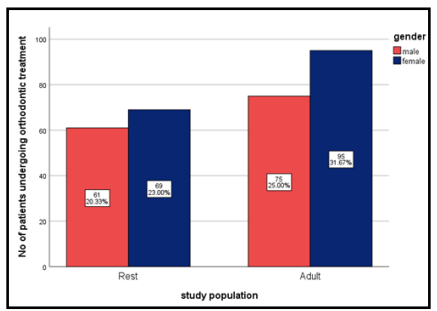

Graph 4: The frequency curve depicts the mean age at which more number of patients underwent orthodontic treatment. It is observed that the highest frequency was observed at the mean age of 20 years.

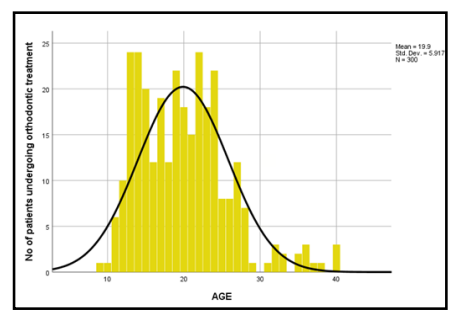

Graph 5: The pie chart showing the frequency of study population who underwent orthodontic treatment. It was observed that the highest frequency was observed in adults (57\%).

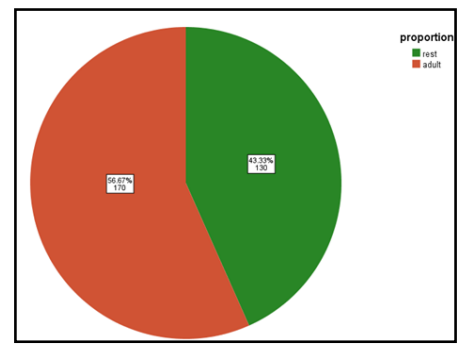

ably more patients cited aesthetics over functional considerations. [29]. The motivating factors for adults seeking orthodontic treatment lay primarily in the enhancement of dentofacial aesthetics and its accompanying improvement in self-confidence. The selfperception of treatment needs in older adults may be different from the treatment needs evaluated by orthodontic expert [30] Livas and Delli [31] have indicated that adults persistently underestimated the definitive treatment need as determined in terms of dental health.

It is generally known that women have a higher interest towards orthodontic treatment than do men [32, 33]. This study showed similar results in that women (55\%) had a significantly higher rate of interest than did men (45\%) in the total sampled population. However, no statistically significant differences were observed between the sexes in any of the age groups, indicating that par- ticipants of both sexes even at the age of 40 years had the same level of interest towards orthodontic treatment. Adult patients may have distinctive characteristics that require specific treatment approaches. A multidisciplinary team may be needed to maximise treatment outcomes by combining orthodontic, restorative, and periodontics treatment principles.Our institution is passionate about high quality evidence based research and has excelled in various fields [34-44].

Future studies can be conducted on various aspects such as patients' perception on undergoing orthodontic treatment and factors that influence the treatment such as socio economic status and their knowledge to correct their malocclusion. Long-term follow- up studies can also be conducted to check the rise in the trend of orthodontic treatments. 


\section{Conclusion}

Within the limits of the study, it can be concluded that in a university hospital based setting, adults seeking orthodontic treatment are proportionately greater than adolescents and children and among adult patients both males and females were equally likely to seek orthodontic treatment.

\section{Authors Contribution}

First author, sandhya performed the data collection by reviewing patient details, filtering required data, analysing and interpreting statistics and contributed to manuscript writing.

Second author, Dr. Harish Babu contributed to conception of study title, study design, analysed the collected data, statistics and interpretation and also critically revised the manuscript.

Third author, Dr. Senthil Murugan P participated in the study and revised the manuscript. All the three authors have discussed the results and contributed to the final manuscript.

\section{Acknowledgement}

This research was supported by saveetha dental college and hospital. We thank the department of Orthodontics, Saveetha Dental College for providing insight and expertise that greatly assisted this research.

\section{References}

[1]. Klages U, Claus N, Wehrbein H, Zentner A. Development of a questionnaire for assessment of the psychosocial impact of dental aesthetics in young adults. Eur J Orthod. 2006 Apr 1;28(2):103-11.

[2]. Dias PF, Gleiser R. Orthodontic treatment need in a group of 9-12-year-old Brazilian schoolchildren. Braz Oral Res. 2009 Apr-Jun;23(2):182-9.Pubmed PMID: 19684953.

[3]. Kiyak HA. Does orthodontic treatment affect patients' quality of life?. J. Dent. Educ. 2008 Aug;72(8):886-94.

[4]. Nattrass C, Sandy JR. Adult orthodontics a review. Br J Orthod. 1995 Nov $1 ; 22(4): 331-7$

[5]. Adeyemi AT, Denloye OO, Bankole OO. Knowledge and attitude of some Nigerian dentists concerning the use of space maintainers in Dentistry. Niger. Dent. J. 2008;15.

[6]. Klages U, Bruckner A, Zentner A. Dental aesthetics, self-awareness, and oral health-related quality of life in young adults. Eur J Orthod. 2004 Oct 1;26(5):507-14.

[7]. Tan EL, Song YL, Zhang Z, Yong KJ, Zhang Y, Yeo X. Orthodontic treatment in National Dental Centre of Singapore: Trends toward higher proportion of adult patients. APOS Trends Orthod. 2019;9:89-93.

[8]. Jayachandar D, Dinesh SS. Factors affecting patient's desire for seeking orthodontic treatment. Int. J. Orthod. Rehabil. 2016 Jul 1;7(3):89.

[9]. Mandall NA, Wright J, Conboy F, Kay E, Harvey L, O’Brien KD. Index of orthodontic treatment need as a predictor of orthodontic treatment uptake. Am J Orthod Dentofacial Orthop. 2005 Dec 1;128(6):703-7.

[10]. Kerosuo H, Kerosuo E, Niemi M, Simola H. The need for treatment and satisfaction with dental appearance among young Finnish adults with and without a history of orthodontic treatment. J Orofac Orthop. 2000;61(5):33040.Pubmed PMID: 11037685.

[11]. Hassan AH, Amin HE. Association of orthodontic treatment needs and oral health-related quality of life in young adults. Am J Orthod Dentofacial Orthop. 2010 Jan 1;137(1):42-7.

[12]. Hafeez N. Accessory foramen in the middle cranial fossa. Res J Pharm Technol. 2016;9(11):1880-2.

[13]. Krishnan RP, Ramani P, Sherlin HJ, Sukumaran G, Ramasubramanian A Jayaraj G, et al. Surgical Specimen Handover from Operation Theater to Laboratory: A Survey. Ann Maxillofac Surg. 2018 Jul-Dec;8(2):234-238. Pubmed PMID: 30693238.
[14]. Somasundaram S, Ravi K, Rajapandian K, Gurunathan D. Fluoride Content of Bottled Drinking Water in Chennai, Tamilnadu. J Clin Diagn Res. 2015 Oct;9(10):ZC32-4.Pubmed PMID: 26557612.

[15]. Felicita AS. Orthodontic extrusion of Ellis Class VIII fracture of maxillary lateral incisor - The sling shot method. Saudi Dent J. 2018 Jul;30(3):265269.Pubmed PMID: 29942113.

[16]. Kumar S, Rahman R. Knowledge, awareness, and practices regarding biomedical waste management among undergraduate dental students. Asian J Pharm Clin Res. 2017;10(8):341.

[17]. Gurunathan D, Shanmugaavel AK. Dental neglect among children in Chennai. J Indian Soc Pedod Prev Dent. 2016 Oct 1;34(4):364.

[18]. Sneha S. Knowledge and awareness regarding antibiotic prophylaxis for infective endocarditis among undergraduate dental students. Asian J Pharm Clin Res. 2016 Oct 1:154-9.

[19]. Dhinesh B, Lalvani JI, Parthasarathy M, Annamalai K. An assessment on performance, emission and combustion characteristics of single cylinder diesel engine powered by Cymbopogon flexuosus biofuel. Energy Convers. Manag.. 2016 Jun 1;117:466-74.

[20]. Choudhari S, Thenmozhi MS. Occurrence and Importance of Posterior Condylar Foramen. Res J Pharm Technol. 2016;9(8): 11-43.

[21]. Paramasivam A, Vijayashree Priyadharsini J, Raghunandhakumar S. N6adenosine methylation (m6A): a promising new molecular target in hypertension and cardiovascular diseases. Hypertens Res. 2020 Feb;43(2):153154.Pubmed PMID: 31578458.

[22]. Wu F, Zhu J, Li G, Wang J, Veeraraghavan VP, Krishna Mohan S, et al. Biologically synthesized green gold nanoparticles from Siberian ginseng induce growth-inhibitory effect on melanoma cells (B16). Artif Cells Nanomed Biotechnol. 2019 Dec;47(1):3297-3305.Pubmed PMID: 31379212.

[23]. Palati S, Ramani P, Shrelin HJ, Sukumaran G, Ramasubramanian A, Don $\mathrm{KR}$, et al. Knowledge, Attitude and practice survey on the perspective of oral lesions and dental health in geriatric patients residing in old age homes. Indian J Dent Res. 2020 Jan-Feb;31(1):22-25.Pubmed PMID: 32246676.

[24]. Saravanan M, Arokiyaraj S, Lakshmi T, Pugazhendhi A. Synthesis of silver nanoparticles from Phenerochaete chrysosporium (MTCC-787) and their antibacterial activity against human pathogenic bacteria. Microb Pathog. 2018 Apr;117:68-72.Pubmed PMID: 29427709.

[25]. Govindaraju L, Gurunathan D. Effectiveness of Chewable Tooth Brush in Children-A Prospective Clinical Study. J Clin Diagn Res. 2017 Mar;11(3):ZC31-ZC34.Pubmed PMID: 28511505.

[26]. Vijayakumar Jain S, Muthusekhar MR, Baig MF, Senthilnathan P, Loganathan S, Abdul Wahab PU, et al. Evaluation of Three-Dimensional Changes in Pharyngeal Airway Following Isolated Lefort One Osteotomy for the Correction of Vertical Maxillary Excess: A Prospective Study. J Maxillofac Oral Surg. 2019 Mar;18(1):139-146.Pubmed PMID: 30728705.

[27]. Kim Y. Study on the perception of orthodontic treatment according to age: A questionnaire survey. Korean J Orthod. 2017 Jul;47(4):215-221.Pubmed PMID: 28670562.

[28]. Patel D, Mehta F, Mehta N. Aesthetic orthodontics: an overview. Orthod. J. Nepal. 2014 Dec 31;4(2):38-43.

[29]. Singh P. Adult orthodontic patients in primary care and their motivation for seeking treatment. Orthodontic Update. 2016 Apr 2;9(2):69-72.

[30]. Josefsson E, Bjerklin K, Lindsten R. Factors determining perceived orthodontic treatment need in adolescents of Swedish and immigrant background. Eur J Orthod. 2009 Feb;31(1):95-102.Pubmed PMID: 19028671.

[31]. Livas C, Delli K. Subjective and objective perception of orthodontic treatment need: a systematic review. Eur J Orthod. 2013 Jun;35(3):347-53.Pubmed PMID: 22250076.

[32]. Tayer BH, Burek MJ. A survey of adults' attitudes toward orthodontic therapy. Am. J. Orthod. 1981 Mar 1;79(3):305-15.

[33]. Tulloch JF, Shaw WC, Underhill C, Smith A, Jones G, Jones M. A comparison of attitudes toward orthodontic treatment in British and American communities. Am J Orthod. 1984 Mar;85(3):253-9.Pubmed PMID: 6584034.

[34]. Vijayashree Priyadharsini J. In silico validation of the non-antibiotic drugs acetaminophen and ibuprofen as antibacterial agents against red complex pathogens. J Periodontol. 2019 Dec;90(12):1441-1448.Pubmed PMID: 31257588.

[35]. Pc J, Marimuthu T, Devadoss P, Kumar SM. Prevalence and measurement of anterior loop of the mandibular canal using CBCT: A cross sectional study. Clin Implant Dent Relat Res. 2018 Apr 6;20(4):531-4.

[36]. Ramesh A, Varghese S, Jayakumar ND, Malaiappan S. Comparative estimation of sulfiredoxin levels between chronic periodontitis and healthy patients - A case-control study. J Periodontol. 2018 Oct;89(10):1241-1248.Pubmed PMID: 30044495

[37]. Ramadurai N, Gurunathan D, Samuel AV, Subramanian E, Rodrigues SJ. Effectiveness of $2 \%$ Articaine as an anesthetic agent in children: randomized controlled trial. Clin. Oral Investig. 2019 Sep;23(9):3543-50.

[38]. Sridharan G, Ramani P, Patankar S, Vijayaraghavan R. Evaluation of salivary 
metabolomics in oral leukoplakia and oral squamous cell carcinoma. J. Oral Pathol. Med. 2019 Apr;48(4):299-306.

[39]. Ezhilarasan D, Apoorva VS, Ashok Vardhan N. Syzygium cumini extract induced reactive oxygen species-mediated apoptosis in human oral squamous carcinoma cells. J Oral Pathol Med. 2019 Feb;48(2):115-121.Pubmed PMID: 30451321.

[40]. Mathew MG, Samuel SR, Soni AJ, Roopa KB. Evaluation of adhesion of Streptococcus mutans, plaque accumulation on zirconia and stainless steel crowns, and surrounding gingival inflammation in primary molars: randomized controlled trial. Clin Oral Investig. 2020 Sep;24(9):1-6.Pubmed PMID: 31955271.

[41]. Samuel SR. Can 5-year-olds sensibly self-report the impact of developmental enamel defects on their quality of life? Int J Paediatr Dent. 2021
Mar;31(2):285-286.Pubmed PMID: 32416620.

[42]. R H, Ramani P, Ramanathan A, R JM, S G, Ramasubramanian A, et al. CYP2 C9 polymorphism among patients with oral squamous cell carcinoma and its role in altering the metabolism of benzo[a]pyrene. Oral Surg Oral Med Oral Pathol Oral Radiol. 2020 Sep;130(3):306-312.Pubmed PMID: 32773350 .

[43]. Chandrasekar R, Chandrasekhar S, Sundari KKS, Ravi P. Development and validation of a formula for objective assessment of cervical vertebral bone age. Prog Orthod. 2020 Oct 12;21(1):38.Pubmed PMID: 33043408.

[44]. Vijayashree Priyadharsini J, Smiline Girija AS, Paramasivam A. In silico analysis of virulence genes in an emerging dental pathogen A. baumannii and related species. Arch Oral Biol. 2018 Oct;94:93-98.Pubmed PMID: 30015217. 